\title{
Digital subtraction myelography in the investigation of post-dural puncture headache in 27 patients: technical note
}

\author{
Wouter I. Schievink, MD, ${ }^{1}$ M. Marcel Maya, MD, ${ }^{2}$ and Franklin G. Moser, MD, MMM ${ }^{2}$ \\ Departments of ${ }^{1}$ Neurosurgery and ${ }^{2}$ Radiology, Cedars-Sinai Medical Center, Los Angeles, California
}

\begin{abstract}
OBJECTIVE Post-dural puncture headaches are common, and the treatment of such headaches can be complex when they become chronic. Among patients with spontaneous spinal CSF leaks, digital subtraction myelography (DSM) can localize the exact site of the leak when an extradural CSF collection is present, and it can also demonstrate CSF-venous fistulas in those without an extradural CSF collection. The authors now report on the use of DSM in the management of patients with chronic post-dural puncture headaches.
\end{abstract}

METHODS The patient population consisted of a consecutive group of 27 patients with recalcitrant post-dural puncture headache that had lasted from 2 to 150 months (mean 26 months).

RESULTS The mean age of the 17 women and 10 men was 39.1 years (range 18-77 years). An extensive extradural CSF collection was present in 5 of the 27 patients, and DSM was able to localize the exact site of the dural defect in all 5 patients. Among the 22 patients who did not have an extradural CSF collection, DSM showed a CSF-venous fistula in 1 patient $(5 \%)$. Three other patients had a small pseudomeningocele at the level of the dural puncture. Percutaneous glue injection or microsurgical repair resulted in resolution of symptoms in 8 of the 9 patients in whom an abnormality had been identified on imaging.

CONCLUSIONS Digital subtraction myelography is able to precisely localize the dural puncture site in patients with a post-dural puncture headache and an extensive extradural CSF collection, and it may rarely detect a CSF-venous fistula in such patients without an extradural CSF collection.

https://thejns.org/doi/abs/10.3171/2016.11.SPINE16968

KEY WORDS headache; low-pressure syndrome; CT; MRI; cerebrospinal fluid; diagnostic technique

$\mathrm{P}$ OST-DURAL puncture headaches are common, occurring in up to one-third of patients following lumbar puncture. . $^{17,16,18,19}$ Fortunately, the headache usually resolves spontaneously, and the success rate of epidural blood patching in those patients with persistent symptoms is high. Rarely, the headache becomes recalcitrant. The treatment of such recalcitrant headaches-herein defined as post-dural puncture headaches that persist in spite of an epidural blood patch-can be complex, especially when headaches become chronic, lasting for months or even years. Digital subtraction myelography (DSM) is a radiographic technique that has been used extensively in patients with spontaneous spinal CSF leaks. , $^{3,410,11}$ In such patients with spontaneous intracranial hypotension, DSM can localize the exact site of the CSF leak when an extradural CSF collection is present, $3,4,10,11$ and it can also demonstrate the presence of spontaneous CSF-venous fistulas in those without an extradural CSF collection. ${ }^{14,15}$ We now report on the use of DSM in the management of patients with chronic post-dural puncture headaches.

\section{Methods \\ Patient Population}

This study was approved by the Cedars-Sinai Medical Center institutional review board. The patient population consisted of a consecutive group of 27 patients with recalcitrant post-dural puncture headache who underwent DSM during a 20-month period. The diagnosis of postdural puncture headache was made using the criteria of the International Classification of Headache Disorders, third edition. ${ }^{2}$ In all patients, the DSM technique as described by Hoxworth and colleagues ${ }^{3,4}$ was used with some minor modifications. Briefly, DSM is performed after induction 
of general endotracheal anesthesia with deep paralysis and suspended respiration for maximal detail and temporal resolution. Patients are positioned prone in a biplane angiography suite, with tilt table capability. Pillows or foam padding are placed to reduce lumbar lordosis, and to overcome thoracic kyphosis. A fluoroscopically guided lumbar puncture is performed at the L2-3 level with a 20 -gauge spinal needle, and an opening pressure is obtained thus (prone under general endotracheal anesthesia) at this time. Accurate needle position is confirmed with an injection of $0.5 \mathrm{ml}$ of Omnipaque. Patients are then further positioned based on the area of interest, tilting the table to achieve contrast flow to the cervicothoracic spine. Finally, contrast is injected manually at $1 \mathrm{ml} / \mathrm{second}$ with suspended respiration for 40-60 seconds, while acquiring biplane subtraction images at 2 frames/second. Patients with a dorsal extradural fluid collection undergo DSM in a supine position, to maximize leak detection. In this subset of patients, first a lumbar drain is placed at the L2-3 level under fluoroscopic guidance while they are prone. A standard lumbar external drainage catheter is introduced via a Tuohy needle. The intrathecal position of the catheter is confirmed with $0.5 \mathrm{ml}$ of Omnipaque injection. After securing the drain with Tegaderm $(3 \mathrm{M})$, the patient is repositioned supine for the DSM as described above.

\section{Results}

The mean age of the 17 women and 10 men was 39.1 years (range 18-77 years). All patients had presented with orthostatic headaches. The duration of symptoms ranged from 2 to 150 months (mean 26 months). All patients had undergone brain MRI examination, and this showed brain sagging or pachymeningeal enhancement in 3 patients. The cause of dural puncture was a diagnostic lumbar puncture in 15 patients, epidural anesthesia in 4 patients, epidural steroid injection in 3 patients, lumbar drain placement in 3 patients, and in 2 patients the exact cause could not be determined and could have been a lumbar puncture, lumbar drain placement, or placement of a lumboperitoneal catheter. Prior to DSM, 25 patients had undergone 2 or more epidural blood patches, and 2 patients had undergone a single epidural blood patch.

Five of the 27 patients had evidence for a CSF leak on spinal imaging; i.e., the presence of an extensive extradural CSF collection (Figs. 1 and 2) (Table 1). The CSF col-
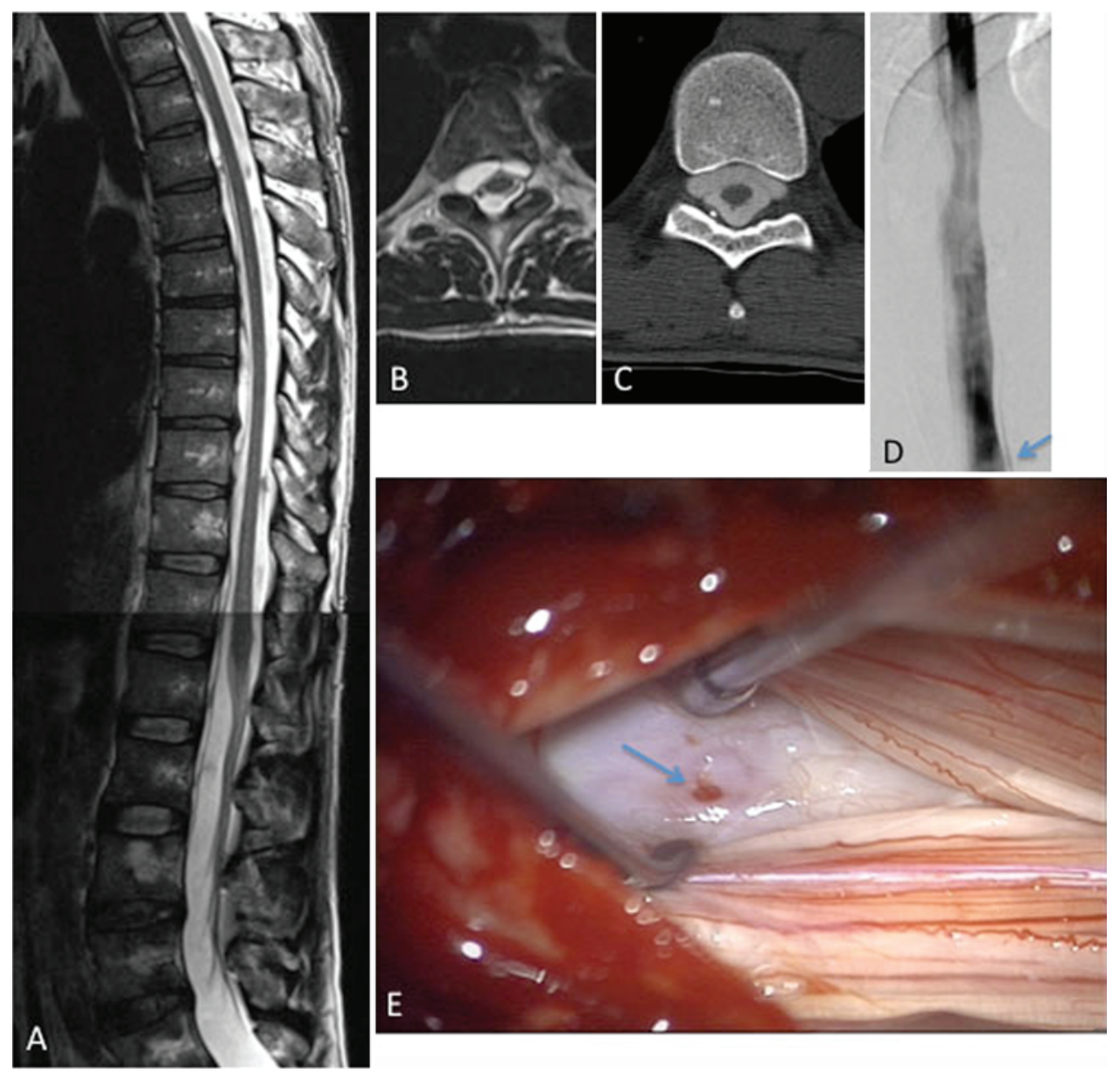

FIG. 1. Imaging of a ventral post-dural puncture CSF leak of 12 years' duration. Sagittal (A) and axial (B) T2-weighted MRI sequences show an extensive extradural CSF collection, which is confirmed on a postmyelography CT scan (C). A DSM study (D) shows the exact location of the CSF leak (arrow) at the L2-3 level, which is confirmed intraoperatively (E), where a small ventral dural puncture hole was visualized (arrow). Figure is available in color online only. 

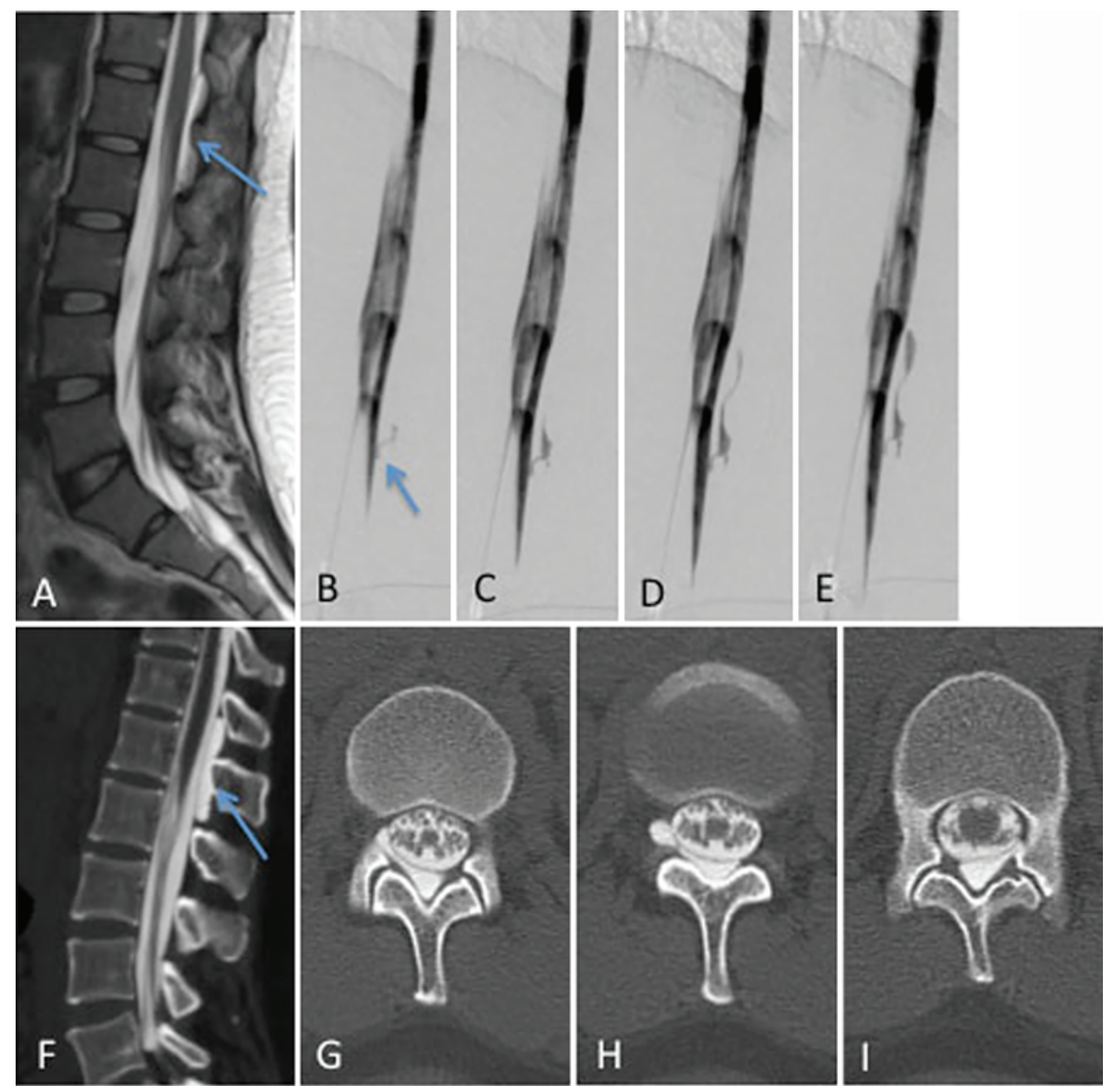

FIG. 2. Imaging of a dorsal post-dural puncture CSF leak. Sagittal T2-weighted MRI sequence (A) shows an upper lumbar dorsal extradural CSF collection (arrow). The DSM sequences (B-E) show the exact location of the CSF leak at the L-2 level (B, arrow). Post-DSM reconstructed sagittal $(\mathbf{F})$ and axial $(\mathbf{G}-\mathbf{I})$ CT scans show the extent of the dorsal extradural CSF collection. Figure is available in color online only.

lection was ventral in 3 of these patients and dorsal in 2. The ventral extradural CSF collection extended over 1824 levels (mean 21) and the dorsal extradural CSF collections over 2-4 levels (mean 3). The DSM study was able to localize the exact site of the dural defect in all 5 patients. Among the 22 patients who did not have an extensive extradural CSF collection on spinal imaging, DSM showed a
CSF-venous fistula in 1 patient (5\%) (Fig. 3). Also, a small dorsal pseudomeningocele measuring $2-3 \mathrm{~mm}$ was found on spinal imaging at the site of dural puncture in 3 of the 22 patients who did not have an extensive extradural CSF collection on spinal imaging (Fig. 4. In the remaining 18 patients, DSM did not show any abnormality.

Percutaneous glue injections $(\mathrm{n}=1)$ or microsurgical

\section{TABLE 1. Clinical and radiographic characteristics in 9 patients with post-dural puncture headache and an abnormality identified on imaging}

\begin{tabular}{clll}
\hline $\begin{array}{c}\text { Sex, Age } \\
\text { (yrs) }\end{array}$ & \multicolumn{1}{c}{ Type of Dural Puncture } & \multicolumn{1}{c}{ MRI \& Post-DSM CT } & DSM Finding \\
\hline F, 33 & Spinal tap & Ventral extradural CSF collection from C-4 to L-4 & CSF leak site at L2-3 \\
\hline M, 48 & Spinal tap & Ventral extradural CSF collection from C-3 to L-3 & CSF leak site at L2-3 \\
\hline F, 22 & Spinal tap, lumbar drain, or lumboperitoneal shunt & Ventral extradural CSF collection from C-1 to L-5 & CSF leak site at L3-4 \\
\hline F, 35 & Spinal tap & Dorsal extradural CSF collection from T-6 to L-4 & CSF leak site at L3-4 \\
\hline F, 33 & Epidural (vaginal delivery) & Dorsal extradural CSF collection from L-1 to L-2 & CSF leak site at L-2 \\
\hline F, 39 & Spinal tap & Normal & Rt L3-4 \& L4-5 CSF-venous fistulas \\
\hline M, 48 & Spinal tap & Pseudomeningocele $(2 \mathrm{~mm})$ at L3-4 & Normal \\
\hline F, 28 & Spinal tap & Pseudomeningocele $(3 \mathrm{~mm})$ at L4-5 & Normal \\
\hline F, 36 & Lumbar drain & Pseudomeningocele $(2 \mathrm{~mm})$ at L3-4 & Normal \\
\hline
\end{tabular}




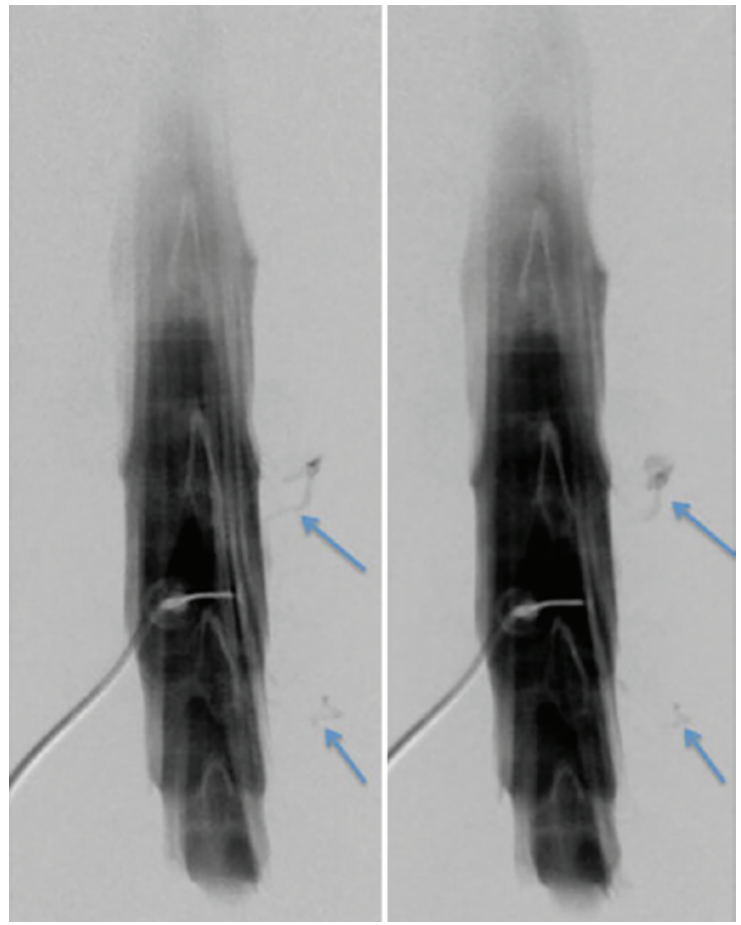

FIG. 3. Imaging of post-dural puncture CSF-venous fistulas. The DSM sequences show CSF-venous fistulas in the right L3-4 and L4-5 neural foramina (arrows). Figure is available in color online only. repair of the dural tear $(n=4)$ resulted in complete resolution of symptoms in all 5 patients with an extradural CSF collection (follow-up 4-21 months, mean 12 months). Among the 4 patients without an extensive extradural CSF collection in whom an anatomical target could be identified, microsurgical repair of the CSF-venous fistula or small pseudomeningocele resulted in resolution of symptoms in 3 patients, whereas 1 patient who underwent repair of a pseudomeningocele reported no change in orthostatic headaches postoperatively (follow-up 8-20 months, mean 14 months). Postprocedure imaging confirmed radiographic resolution in all 9 patients in whom an abnormality had been identified on imaging.

\section{Discussion}

Radiographic evidence of a CSF leak is very common shortly after a lumbar puncture. In 1 study, CSF leakage could be identified within a few days of a diagnostic lumbar puncture in $100 \%$ of patients with a post-dural puncture headache, and also in $50 \%$ of patients without a post-dural puncture headache. ${ }^{19}$ In patients with prolonged headache after a lumbar puncture, however, spinal imaging results are generally normal, and extradural CSF collections have only rarely been reported.,.$^{917}$

In this study we used DSM in patients with an extensive extradural CSF collection to localize the exact site of the dural puncture to help guide directed treatment; i.e., per-
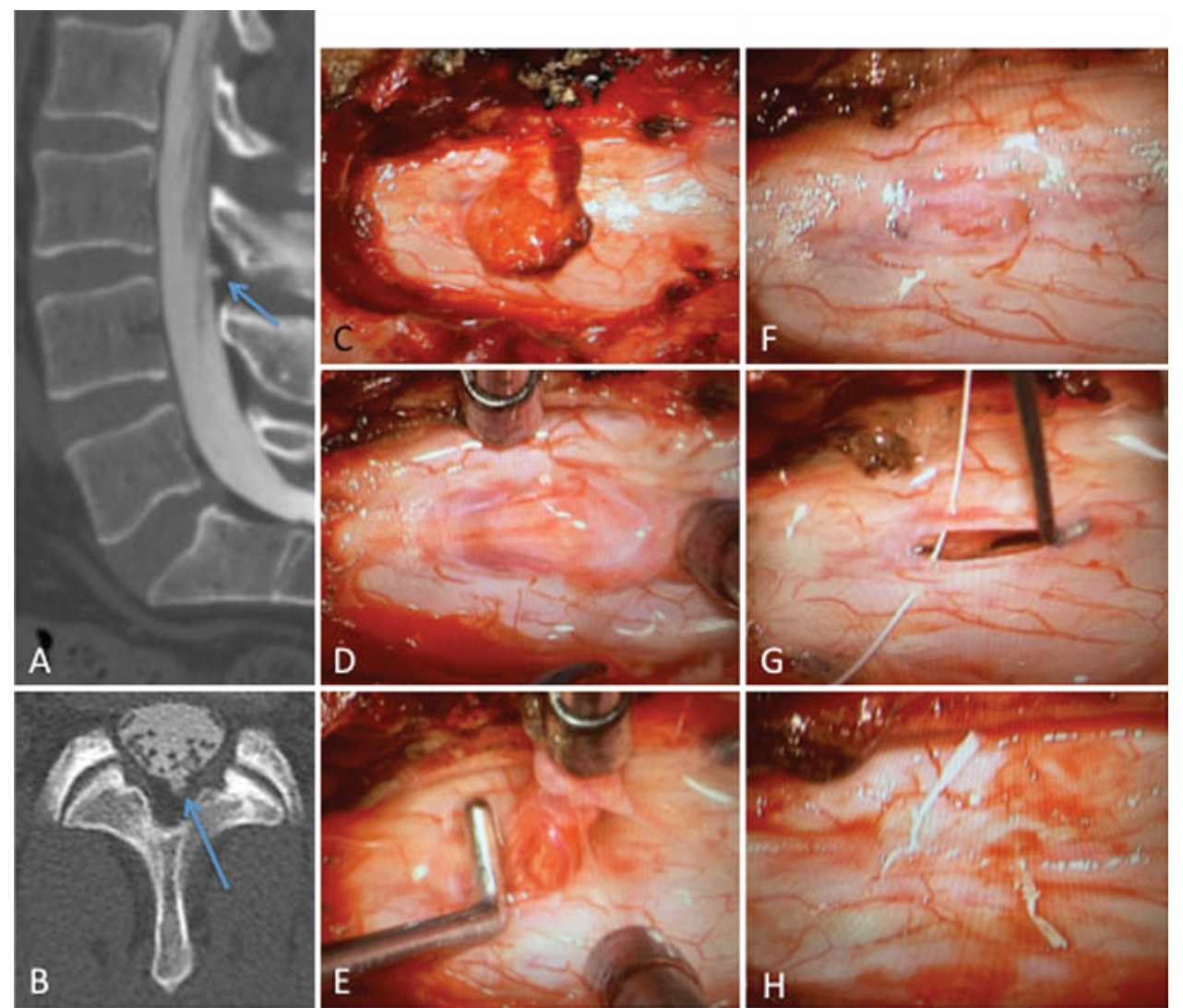

FIG. 4. Imaging of a small post-dural puncture pseudomeningocele. Post-DSM reconstructed sagittal (A) and axial (B) CTs show a 2-mm pseudomeningocele at the site of a lumbar puncture at the L3-4 level (arrows). Intraoperative photographs (C-H) show microsurgical dissection and repair of the dural tear. Figure is available in color online only. 
cutaneous glue injection or microsurgical repair. Digital subtraction myelography was necessary because the extradural fluid collections extended over many levels, and the level of the dural puncture was not known in any of these patients. This group of patients included individuals with post-dural puncture CSF leaks of unusually long duration-up to 12 years. The CSF leaks of longest duration were all located ventrally. Such ventral CSF leaks, either iatrogenic or spontaneous, have been reported previously to have a tendency to become chronic. ${ }^{12,13}$

In this study we also used DSM to look for a CSF-venous fistula in patients with post-dural puncture headache who had no extradural fluid collection. We have recently described such fistulas in patients with spontaneous intracranial hypotension who have no evidence for a CSF leak on conventional non-DSM imaging. ${ }^{14,15}$ Others have confirmed the existence of these CSF-venous fistulas among patients with spontaneous intracranial hypotension, by using dynamic CT myelography. ${ }^{5,6}$ Moreover, CSF-venous fistulas have been detected in patients following lumbar puncture, and it has been postulated that these fistulas could be the cause of post-dural puncture headaches. ${ }^{8}$ However, we found such a CSF-venous fistula in only 1 of 22 patients with post-dural puncture headache who had no extradural fluid collection.

\section{Conclusions}

The use of DSM in chronic post-dural puncture headache is limited, and it was not able to detect a source of CSF leakage in the great majority of patients who had normal, routine (i.e., postmyelography CT) spine imaging. The treatment of these patients is complex and, in addition to medical treatment, may include further epidural blood patching, percutaneous glue injections, or even surgical exploration.

\section{References}

1. Carbaat PA, van Crevel H: Lumbar puncture headache: controlled study on the preventive effect of 24 hours' bed rest. Lancet 2:1133-1135, 1981

2. Headache Classification Committee of the International Headache Society: The International Classification of Headache Disorders, 3rd edition. Cephalalgia 33:629-808, 2013

3. Hoxworth JM, Patel AC, Bosch EP, Nelson KD: Localization of a rapid CSF leak with digital subtraction myelography. AJNR Am J Neuroradiol 30:516-519, 2009

4. Hoxworth JM, Trentman TL, Kotsenas AL, Thielen KR, Nelson KD, Dodick DW: The role of digital subtraction myelography in the diagnosis and localization of spontaneous spinal CSF leaks. AJR Am J Roentgenol 199:649-653, 2012

5. Kranz PG, Amrhein TJ, Schievink WI, Karikari IO, Gray L: The "hyperdense paraspinal vein" sign: a marker of CSF-venous fistula. AJNR Am J Neuroradiol 37:1379-1381, 2016

6. Kumar N, Diehn FE, Carr CM, Verdoorn JT, Garza I, Luetmer PH, et al: Spinal CSF venous fistula: A treatable etiology for CSF leaks in craniospinal hypovolemia. Neurology 86:2310-2312, 2016

7. Kuntz KM, Kokmen E, Stevens JC, Miller P, Offord KP, Ho
MM: Post-lumbar puncture headaches: experience in 501 consecutive procedures. Neurology 42:1884-1887, 1992

8. Lin PM, Clarke J: Spinal fluid-venous fistula: a mechanism for intravascular pantopaque infusion during myelography. Report of two cases. J Neurosurg 41:773-776, 1974

9. Nurboja B, Rezajooi K, Newton MC, Casey AT: Spinal meningocele due to iatrogenic dural puncture during epidural analgesia for childbirth: 5 -year history of headache with a spinal etiology. J Neurosurg Spine 11:764-767, 2009

10. Phillips CD, Kaptain GJ, Razack N: Depiction of a postoperative pseudomeningocele with digital subtraction myelography. AJNR Am J Neuroradiol 23:337-338, 2002

11. Schievink WI: Novel neuroimaging modalities in the evaluation of spontaneous cerebrospinal fluid leaks. Curr Neurol Neurosci Rep 13:358, 2013

12. Schievink WI, Maya MM: Ventral spinal cerebrospinal fluid leak as the cause of persistent post-dural puncture headache in children. J Neurosurg Pediatr 11:48-51, 2013

13. Schievink WI, Maya MM, Nuño M: Chronic cerebellar hemorrhage in spontaneous intracranial hypotension: association with ventral spinal cerebrospinal fluid leaks: clinical article. J Neurosurg Spine 15:433-440, 2011

14. Schievink WI, Moser FG, Maya MM: CSF-venous fistula in spontaneous intracranial hypotension. Neurology 83:472473, 2014

15. Schievink WI, Moser FG, Maya MM, Prasad RS: Digital subtraction myelography for the identification of spontaneous spinal CSF-venous fistulas. J Neurosurg Spine 24:960-964, 2016

16. Strupp M, Schueler O, Straube A, Von Stuckrad-Barre S, Brandt T: "Atraumatic" Sprotte needle reduces the incidence of post-lumbar puncture headaches. Neurology 57:23102312, 2001

17. van Crevel H, Muizelaar JP, van Ouwerkerk RC: [Treatment of long-lasting post-spinal puncture headache.] Ned Tijdschr Geneeskd 131:2003-2005, 1987 (Dutch)

18. van Oosterhout WP, van der Plas AA, van Zwet EW, Zielman R, Ferrari MD, Terwindt GM: Postdural puncture headache in migraineurs and nonheadache subjects: a prospective study. Neurology 80:941-948, 2013

19. Wang YF, Fuh JL, Lirng JF, Chen SP, Hseu SS, Wu JC, et al: Cerebrospinal fluid leakage and headache after lumbar puncture: a prospective non-invasive imaging study. Brain 138:1492-1498, 2015

\section{Disclosures}

The authors report no conflict of interest concerning the materials or methods used in this study or the findings specified in this paper.

\section{Author Contributions}

Conception and design: Schievink. Acquisition of data: all authors. Analysis and interpretation of data: all authors. Drafting the article: Schievink. Critically revising the article: all authors. Reviewed submitted version of manuscript: Schievink. Approved the final version of the manuscript on behalf of all authors: Schievink. Statistical analysis: Schievink.

\section{Correspondence}

Wouter I. Schievink, Department of Neurosurgery, Cedars-Sinai Medical Center, 127 S San Vicente Blvd., Ste. A6600, Los Angeles, CA 90048. email: schievinkw@cshs.org. 